\title{
A pilot study on effectiveness of oral mucositis pain control in hematopoietic stem cell transplant patients
}

\author{
Shu Ping Wong, Farida Islahudin* \\ Faculty Pharmacy, Universiti Kebangsaan Malaysia, Jalan Raja Muda Abdul Aziz, Kuala Lumpur, Malaysia
}

\begin{tabular}{l}
\hline ARTICLE INFO \\
\hline Received on: 07/01/2019 \\
Accepted on: $12 / 02 / 2019$ \\
Available online: $30 / 03 / 2019$
\end{tabular}

Key words:

Mucositis, stem cell transplant, WHO oral toxicity scale, OMDQ, pain.

\begin{abstract}
Effectiveness of oral mucositis (OM) pain control with the current standard of care management was assessed using clinician and self-reported scales in hematopoietic stem cell transplant (HSCT) patients. A prospective observational study was performed using clinician-assessed [World Health Organization (WHO)] Oral Toxicity Scales and selfreported scales [Oral Mucositis Daily Questionnaires (OMDQ)]. A total of 23 HSCT patients were included in the study. There were 100 recorded days of OM using WHO scores, and 144 recorded days of OM using OMDQ. A total of $14 / 23(60.9 \%)$ patients experienced mucositis. The presence of OM was significantly associated with increase in actual body weight $\left[t_{(21)}=2.15, p=0.044\right]$, body surface area (BSA) $\left[t_{(21)}=2.31, p=0.031\right]$ and body mass index (BMI) $\left[t_{(21)}=2.13, p=0.044\right]$, longer hospital stays $\left[t_{(21)}=2.45, p=0.023\right]$, and busulphan-based regimens $(\chi=4.32$, $p=0.038)$. The degree of pain relief was significantly inversely correlated to both the degree of WHO graded OM severity $(\rho=-0.586 ; p<0.001)$ and the severity of self-reported pain $(\rho=-0.375 ; p<0.001)$. Both WHO and OMDQ significantly positively correlated in the clinical setting $(p<0.001)$. In conclusion, this study highlights the potential advantages of using patient self-reported scales in the local clinical setting. The use of the OMDQ self-reported scales could lead to earlier changes in therapy and may prove useful in HSCT patients.
\end{abstract}

\section{INTRODUCTION}

Hematopoietic stem cell transplant (HSCT) is an important modality of treatment for patients with hematological malignancies (Abdul Wahid et al., 2014; Rafeah and Fadilah, 2009). However, HSCT is associated with various complications and adverse effects (Wahid, 2013). Unfortunately, 75\%-99\% of patients undergoing HSCT suffer from oral mucositis (OM), which is often associated with significantly poor clinical and economic outcomes (Bensinger et al., 2008). Of all the complications of HSCT, patients view OM as the single most debilitating complication of HSCT (Sonis et al., 2001). OM involves a complex biological process influenced by cytokines, effects of chemotherapy on the epithelium, generation of reactive oxygen species, and bacterial flora of the oral cavity. It

"Corresponding Author

Farida Islahudin, Faculty Pharmacy, Universiti Kebangsaan Malaysia, Jalan Raja Muda Abdul Aziz, Kuala Lumpur, Malaysia. E-mail: faridaislahudin@yahoo.com is postulated to develop in five interdependent phases, which are initiation, primary damage response (messaging and signaling), amplification, ulceration, and healing (Bensinger et al., 2008; Sonis et al., 2001). Severe pain from OM compromises verbal communication and impairs swallowing abilities, impacting nutritional status and compliance to oral medication. This often leads to the use of parenteral narcotics for relief of pain (Sonis et al., 2001).

There are limited data about the characteristics of OM in our population of HSCT, which utilizes high-dose chemotherapy with or without radiotherapy. Influencing factors are still largely conflicting (Bensinger et al., 2008; Chai et al.; 2006; Sonis et al., 2001). We postulate that factors affecting the extent and severity of OM may be influenced by population characteristics (Loh et al., 2013). As for the management of OM, strategies largely focus on preventive approaches. However, there is still a disparity in the evidence supporting any one of the topical agents in the prevention of OM (Bensinger et al., 2008). Although patient-controlled analgesia with morphine is the treatment of choice, topical anesthetics do provide short-term pain relief on an empirical basis 
(Bensinger et al., 2008). These agents, however, do not come without adverse effects.

There is currently no "gold standard" for assessing the severity of OM. Clinical assessment may be based solely on objective assessments of the oral mucosal or a combination of both objective and subjective assessments (Loh et al., 2013; Stiff et al., 2006). The clinician-assessed World Health Organization (WHO) scale (Stiff et al., 2006) is widely used and is sufficiently sensitive for OM caused by both chemotherapy and radiotherapy. However, perceptions of mucositis may differ between patients and clinicians and may lead to inadequate treatment of symptoms. For a more accurate assessment, patient's self-reported tools (Stiff et al., 2006) such as the OM daily questionnaire (OMDQ) have also been used together with the WHO scale (Stiff et al., 2006). The OMDQ is a simple feasible self-monitoring tool that can be used by cancer patients (Stiff et al., 2006). However, the patient's self-reported assessment of OM in our HSCT population has not been extensively studied.

In the Asian population, patients have been known to under-report pain when assessed by clinicians (WHO, 1979). In the Asian population, patients may tend to under-report pain due to a greater negative attitude toward pain and its management (Chen et al., 2012). As such, equipping patients with a selfreporting instrument, independent of intervention by healthcare professionals, may help identify if $\mathrm{OM}$ pain is adequately addressed. Considering the impact of OM on patient's treatment management, quality of life, and healthcare cost, it is imperative to understand more about this condition and its natural course in our patient population. Therefore, the aim of this work was to assess the effectiveness of OM pain control with the current standard of care management using both WHO scores and OMDQ.

\section{MATERIALS AND METHODS}

\section{Study design}

This is a prospective observational pilot study carried out across two HSCT centers, involving a universal sampling of patients consecutively admitted for conditioning regimen. The inclusion criteria were a minimum age of 18 years old, OM WHO grade 0 at the time of receiving conditioning regimen, ability to read, and not receiving investigational agents for OM. Exclusion criteria were subjects who were unlikely to comply with or complete the study (e.g. mental incapacity), and receiving non-myeloablative conditioning regimen as previously defined (Bacigalupo et al., 2009). The study was approved by the National Medical Research and Ethics Committee (ID: 1.5.3.5/244/NF006-14), and all patients gave written consent.

\section{HSCT management}

Conditioning regimens used for autologous transplant were high-dose melphalan (HDM) (melphalan 100-200 mg/m² IV for 2 days) and BEAM (carmustine $300 \mathrm{mg} / \mathrm{m}^{2}$ IV for 1 day, etoposide $200 \mathrm{mg} / \mathrm{m}^{2} \mathrm{IV}$ and cytarabine $200 \mathrm{mg} / \mathrm{m}^{2}$ IV for 4 days, melphalan $140 \mathrm{mg} / \mathrm{m}^{2}$ IV for 1 day) (Bacigalupo et al., 2009). Regimens used for allogenic transplant were $\mathrm{Bu} / \mathrm{Cy}$ (busulphan $1 \mathrm{mg} / \mathrm{kg}$ PO QID for 4 days, cyclophosphamide $60 \mathrm{mg} / \mathrm{kg} \mathrm{IV}$ for 2 days, and mesna $60 \mathrm{mg} / \mathrm{kg}$ IV for 3 days) and Flu/Bu/ATG (fludarabine $30 \mathrm{mg} / \mathrm{m}^{2} \mathrm{IV}$ for 6 days, busulphan $1 \mathrm{mg} / \mathrm{kg}$ PO QID for 4 days, antithymocyte rabbit $2.5 \mathrm{mg}$ for 2 days, or equine 30 $\mathrm{mg} / \mathrm{kg}$ for 3 days) (Bacigalupo et al., 2009). Allogenic transplant patients received methotrexate $32-45 \mathrm{mg} / \mathrm{m}^{2} \mathrm{IV}$ and a starting dose of cyclosporine $6 \mathrm{mg} / \mathrm{kg}$ IV as graft-versus-host disease prophylaxis (Bacigalupo et al., 2009).

\section{Data collection}

Patients were followed up a day before the conditioning regimen (day 0 of study) until discharged. Demographic and clinical data were obtained from hospital records. Daily assessment of OM was performed by healthcare providers using the WHO Oral Toxicity Scale (Zhu et al., 2016). Patients were also taught to record in a daily diary containing the OMDQ scale (Stiff et al., 2006). The study was conducted to respect the patients' anonymity.

\section{WHO oral toxicity scale}

Daily assessment of oral mucosal was performed by healthcare providers using the WHO Oral Toxicity Scale (Zhu et al., 2016). Grade 0 corresponds to an oral cavity with no lesions, grade 1 corresponds to the presence of erythema and soreness, grade 2 corresponds to erythema and ulceration with the ability to eat and drink, grade 3 corresponds to extensive erythema and ulcers with the inability to eat solids, and grade 4 corresponds to the presence of marked erythema, ulceration, and pain where oral alimentation is impossible with/without bleeding.

\section{Oral mucositis daily questionnaire}

Severity of OM was assessed by patients using a daily diary containing the OMDQ scale (Stiff et al., 2006), which was taught to them at enrollment. OMDQ incorporates questions on overall health with a response of $0=$ worst possible to $10=$ perfect health. Severity of mucositis was assessed from $0=$ no soreness to $4=$ extreme soreness. The impact of $\mathrm{OM}$ on functional status was assessed through swallowing, drinking, eating, talking, and sleeping with a response for each task ranging from $0=$ not limited to $4=$ unable to do. Diarrhea was assessed through a response of $0=$ none to $4=$ severe diarrhea, and the overall severity of diarrhea was assessed with a response of $0=$ no diarrhea to $10=$ worst possible diarrhea. A higher score indicated a more severe condition, except for the overall health question.

Patients were also assessed on the effectiveness of the medication given for OM. Effectiveness of medication was assessed on a scale of $0=$ no relief to $4=$ complete relief (Stiff $e t$ al., 2006). Adverse effects of medication and a daily mouthwash record were also added into the diary.

\section{Statistical analyses}

Analyses were done using IBM $^{\circledR}$ SPSS $^{\circledR}$ version 22. According to the WHO and OMDQ scale, mucositis was defined as mucositis (WHO Grade 1-2, OMDQ Q2 response 1-2) and severe mucositis (WHO Grade 3-4, OMDQ Q2 response 3-4) (Vagliano et al., 2011). Correlation was defined as negligible or not correlated (0-0.25), fair correlation $(0.25-0.50)$, moderate-good correlation $(>0.50-0.75)$, and very good to excellent correlation $(>0.75)$ (Manji et al., 2012). Associations of interest were assessed using Fisher's exact test (categorical data), independent- $t$-test (two groups of continuous data), one-way analysis of variance (ANOVA) ( $\geq 3$ groups of continuous data), Spearman's correlation 
coefficient (ordinal data), and Pearson's correlation coefficient (continuous data) and its $p$-value, as appropriate. $p$-value was set at $<0.05$ as significant.

\section{RESULTS}

\section{Demographics}

Table 1 describes the demographic and clinical characteristics of the 23 patients. Collectively, there were 100 recorded days of mucositis by the WHO scale and 144 reported days of OM by the OMDQ scale, with $18 \%$ and $14 \%$ of those days reported as severe OM, respectively. The presence of OM

Table 1. Demographic data and characteristics of study subjects $(n=23)$.

\begin{tabular}{|c|c|}
\hline Patient characteristics & Number of patients \\
\hline \multicolumn{2}{|l|}{ Gender, $n(\%)$} \\
\hline Male & $16(69.6)$ \\
\hline Female & $7(30.4)$ \\
\hline \multicolumn{2}{|l|}{ Ethnicity, $n(\%)$} \\
\hline Malay & $16(69.6)$ \\
\hline Chinese & $3(13.0)$ \\
\hline Indian & $4(17.4)$ \\
\hline Age (years), (mean $\pm \mathrm{SD})$ & $42.9 \pm 13.4$ \\
\hline Actual body weight $(\mathrm{kg}),($ mean $\pm \mathrm{SD})$ & $68.5 \pm 25.9$ \\
\hline $\operatorname{BSA}\left(\mathrm{m}^{2}\right),($ mean $\pm \mathrm{SD})$ & $1.8 \pm 0.5$ \\
\hline $\mathrm{BMI}\left(\mathrm{kg} / \mathrm{m}^{2}\right),($ mean $\pm \mathrm{SD})$ & $25.9 \pm 5.0$ \\
\hline \multicolumn{2}{|c|}{$\begin{array}{l}\text { WHO Oral Toxicity Scale peak oral mucositis, } \\
n(\%)\end{array}$} \\
\hline None (Grade 0) & $9(39.1)$ \\
\hline Mild to moderate (Grades 1-2) & $9(39.1)$ \\
\hline Severe (Grades 3-4) & $5(21.8)$ \\
\hline \multicolumn{2}{|l|}{ OMDQ peak oral mucositis, $n(\%)$} \\
\hline None (response 0) & $9(39.1)$ \\
\hline Mild to moderate (response 1-2) & $4(17.4)$ \\
\hline Severe (response 3-4) & $10(43.5)$ \\
\hline \multicolumn{2}{|l|}{ Diagnosis, $n(\%)$} \\
\hline Leukemia & $7(30.5)$ \\
\hline Non-leukemia & $16(69.5)$ \\
\hline Length of stay (day), $($ mean \pm SD) & $19.9 \pm 2.4$ \\
\hline \multicolumn{2}{|l|}{ Transplant Type, $n(\%)$} \\
\hline Autologous & $17(73.9)$ \\
\hline Allogeneic & $6(26.1)$ \\
\hline \multicolumn{2}{|l|}{ Conditioning Regimen, $n(\%)$} \\
\hline BEAM & $11(47.9)$ \\
\hline HDM & $5(21.7)$ \\
\hline $\mathrm{Bu} / \mathrm{Cy}$ & $4(17.4)$ \\
\hline $\mathrm{Flu} / \mathrm{Bu} / \mathrm{ATG}$ & $3(13.0)$ \\
\hline \multicolumn{2}{|l|}{ Methotrexate, $n(\%)$} \\
\hline No & $17(73.9)$ \\
\hline Yes & $6(26.1)$ \\
\hline Mouthwashes/day, $($ mean \pm SD) & $2.55 \pm 1.24$ \\
\hline
\end{tabular}

throughout the study period was observed in the same patients $(n=14,60.9 \%)$ in both the WHO and OMDQ scales, although the severity of the OM reported differed. The mean time to onset of $\mathrm{OM}$ was 12.5 days ( $\mathrm{SD} \pm 2.7$, range: 9-19 days) from chemotherapy and/or radiotherapy administration according to WHO scales, which was significantly different from the 9.4 days ( $\mathrm{SD} \pm 4.1$, range: $1-17$ days) reported by patients through OMDQ $(t=2.397, p=0.024)$. There was no significant difference in the mean days to peak OM or duration of OM between both scores. Mean to peak $\mathrm{OM}$ was at day 14 for both $\mathrm{WHO}(\mathrm{SD} \pm 2.8$, range: 9-19 days) and OMDQ ( $\mathrm{SD} \pm 3.6$, range: $8-23$ days) scores. OM typically lasted for a mean duration of 6.3 days $(\mathrm{SD} \pm 1.97$, range: 3-9 days) according to WHO scores and 9.86 days ( $\mathrm{SD} \pm 4.5$, $1-22$ days) according to patient's OMDQ report $\left[t_{(26)}=2.71, p=\right.$ $0.01]$.

\section{Presence of oral mucositis}

Patients received various types of oral mouthwashes according to local practice. This included OralSeven ${ }^{\circledR}$ mouthwash $(65.2 \%)$ and various other combinations (30.4\%). Only one patient $(4.4 \%)$ did not use any mouthwash. As shown in Table 2, there were several significant factors associated with the incidence of mucositis. A higher actual body weight $\left[t_{(21)}=2.15, p=0.044\right]$, $\mathrm{BSA}\left[t_{(21)}=2.31, p=0.031\right]$, and BMI $\left[t_{(21)}=2.13, p=0.044\right]$ were significantly associated with the presence of $\mathrm{OM}$ in the study population. Those who stayed longer in hospital $(21.2 \pm$ 2.83 days) were also more likely to report OM compared to those with a shorter duration (18.6 \pm 1.94 days) $\left[t_{(21)}=2.45, p=0.023\right)$. Other significant findings related to the presence of OM were busulphan-based therapy that caused OM more than melphalanbased regimens $(\chi=4.32, p=0.038)$.

\section{Pain relief}

A total of seven (30.4\%) patients required topical analgesics, three $(13 \%)$ required systemic morphine, and three $(13 \%)$ required a combination of both. Looking at the 83 individual incidences of documented pain or analgesics administration, 42 $(51.8 \%)$ episodes required topical analgesics, 28 (33.7\%) episodes required systemic morphine, and $13(14.5 \%)$ episodes required a combination of both. A total of $73(88 \%)$ episodes of analgesic administration were graded as having some degree of pain relief. However, the degree of pain relief was inversely correlated to both the degree of WHO graded OM severity $(\rho=-0.586 ; p<0.001)$ and the severity of self-reported pain $(\rho=-0.375 ; p<0.001)$.

It was demonstrated that there was a significantly higher episode of complete pain relief with topical agents as compared to other treatments $(\chi=48.8, p<0.001)$ (Table 3$)$. Conversely, most of the pain episodes requiring systemic morphine only achieved moderate to no relief. A total of three patients reported adverse effects with analgesic use. Two patients were on a combination treatment and reported vomiting and stinging of the oral mucosal. One patient reported stinging of the oral mucosal with topical agents.

\section{Correlation between OMDQ and WHO scores}

Table 4 shows the relationship between patients' reported OMDQ scores with WHO scores by healthcare providers, which were all significantly correlated. Mouth and throat soreness, 
Table 2. Demographic characteristics of patients with and without mucositis $(n=23)$.

\begin{tabular}{|c|c|c|c|}
\hline Patient characteristics & $\begin{array}{c}\text { No mucositis } \\
\text { Grade } 0(n=9)\end{array}$ & $\begin{array}{c}\text { Mucositis } \\
\text { Grades } 1-4,(n=14)\end{array}$ & $p$-value \\
\hline \multicolumn{4}{|l|}{ Gender, $n(\%)$} \\
\hline Male & $7(30.4)$ & $9(39.1)$ & $0.657^{\mathrm{a}}$ \\
\hline Female & $2(8.7)$ & $5(21.8)$ & \\
\hline \multicolumn{4}{|l|}{ Ethnicity, $n(\%)$} \\
\hline Malay & $7(30.4)$ & $9(39.1)$ & $0.771^{\mathrm{a}}$ \\
\hline Chinese & $1(4.4)$ & $2(8.7)$ & \\
\hline Indian & $1(4.4)$ & $3(13.0)$ & \\
\hline Age (years), $($ mean $\pm \mathrm{SD})$ & $49.7 \pm 12.9$ & $38.6 \pm 12.2$ & $0.051^{\mathrm{b}}$ \\
\hline Actual body weight $(\mathrm{kg}),($ mean $\pm \mathrm{SD})$ & $62.4 \pm 12.4$ & $74.6 \pm 13.5$ & $0.044^{\mathrm{b}}$ \\
\hline $\operatorname{BSA}\left(\mathrm{m}^{2}\right),($ mean $\pm \mathrm{SD})$ & $1.7 \pm 0.27$ & $1.9 \pm 0.2$ & $0.031^{\mathrm{b}}$ \\
\hline BMI $\left(\mathrm{kg} / \mathrm{m}^{2}\right),($ mean $\pm \mathrm{SD})$ & $23.6 \pm 4.5$ & $28.3 \pm 5.5$ & $0.044^{\mathrm{b}}$ \\
\hline \multicolumn{4}{|l|}{ Diagnosis, $n(\%)$} \\
\hline Leukemia & $0(0)$ & $7(30.4)$ & $0.086^{\mathrm{a}}$ \\
\hline Non-leukemia & $9(39.1)$ & $7(30.5)$ & \\
\hline Length of stay (day), (mean \pm SD) & $18.6 \pm 1.94$ & $21.2 \pm 2.83$ & $0.023^{\mathrm{b}}$ \\
\hline \multicolumn{4}{|l|}{ Transplant type, $n(\%)$} \\
\hline Autologous & $9(39.1)$ & $8(34.8)$ & $0.072^{\mathrm{a}}$ \\
\hline Allogeneic & $0(0)$ & $6(26.1)$ & \\
\hline \multicolumn{4}{|l|}{ Conditioning Regimen, $n(\%)$} \\
\hline Melphalan-based & $9(39.2)$ & $7(30.4)$ & $0.038^{\mathrm{a}}$ \\
\hline Busulphan-based & $0(0)$ & $7(30.4)$ & \\
\hline \multicolumn{4}{|l|}{ Methotrexate, $n(\%)$} \\
\hline No & $9(39.1)$ & $8(34.8)$ & $0.072^{\mathrm{a}}$ \\
\hline Yes & $0(0)$ & $6(26.1)$ & \\
\hline Mouthwashes/day, $($ mean \pm SD) & $2.3 \pm 1.44$ & $2.8 \pm 1.04$ & $0.344^{\mathrm{b}}$ \\
\hline
\end{tabular}

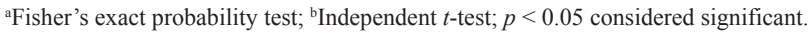

Table 3. Degree of pain relief according to type of analgesics $(n=83)$.

\begin{tabular}{lcccc}
\hline \multicolumn{1}{c}{ Degree of pain relief } & Topical analgesics & Morphine & Combination & \\
& $\boldsymbol{n}=\mathbf{4 3}$ & $\boldsymbol{n}=\mathbf{2 8}$ & $\boldsymbol{n}=\mathbf{1 2}$ & $\boldsymbol{p}$-value \\
\hline No relief, $n(\%)$ & $0(0)$ & $10(12.1)$ & $0(0)$ & $<0.001^{\mathrm{a}}$ \\
Slight relief, $n(\%)$ & $9(10.8)$ & $17(20.4)$ & $6(7.3)$ & \\
Moderate relief, $n(\%)$ & $14(16.9)$ & $1(1.2)$ & $4(4.8)$ & \\
Strong relief, $n(\%)$ & $5(6.0)$ & $0(0)$ & $1(1.2)$ & \\
Complete relief, $n(\%)$ & $15(18.1)$ & $0(0)$ & $1(1.2)$ & $<0.001^{\text {b }}$ \\
Pain relief rate, mean $\pm \mathrm{SD}$ (range) & $2.6 \pm 1.18(1-4)$ & $0.7 \pm 0.55(0-2)$ & $1.8 \pm 0.97(1-4)$ & \\
\hline
\end{tabular}

Pain relief rate $=0$ (no relief) to 4 (complete relief).

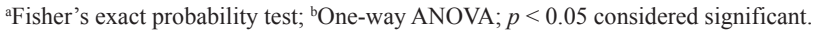

swallowing, eating, drinking, talking, and sleeping had a moderate to good correlation with WHO scores $(\rho=0.50-0.75, p<0.001)$. Overall health, diarrhea, and overall diarrhea had a fair correlation with WHO scores $(\rho=0.25-0.50, p<0.001)$.

\section{DISCUSSION}

Approximately, two-thirds of patients undergoing HSCT experience some degree of OM (Bensinger et al., 2008). The frequency of $\mathrm{OM}$ is dependent on various factors and differs from one population to another (Loh et al., 2013). In this particular work, the incidence of OM was slightly lower than previously reported (Bensinger et al., 2008). However, both the clinician reported WHO and patient-reported OMDQ scales were able to assess the presence of OM successfully, albeit with different results. The patient selfreported OMDQ was able to capture an earlier onset of OM compared to the WHO scale. Patients also reported a longer OM duration than those reported by their clinicians. This suggests that patients may tend to under-report mild pain when enquired by healthcare providers, possibly demonstrating a more reserved behavior found widespread in the Asian population (Chen et al., 2012). 
Table 4. Correlation between OMDQ with the WHO Oral Toxicity Scale $(n=464)$.

\begin{tabular}{lcc}
\hline \multicolumn{1}{c}{ OMDQ } & \multicolumn{2}{c}{ WHO oral toxicity scale } \\
& $\boldsymbol{\rho}$ & $\boldsymbol{p}$-value \\
\hline Overall health & 0.403 & $<0.001$ \\
Mouth and throat soreness & 0.696 & $<0.001$ \\
Swallowing & 0.705 & $<0.001$ \\
Eating & 0.708 & $<0.001$ \\
Drinking & 0.715 & $<0.001$ \\
Talking & 0.600 & $<0.001$ \\
Sleeping & 0.570 & $<0.001$ \\
Overall mouth and throat soreness & 0.693 & $<0.001$ \\
Diarrhea & 0.462 & $<0.001$ \\
Overall diarrhea & 0.495 & $<0.001$ \\
\hline
\end{tabular}

Spearman coefficient $\rho, p<0.05$ considered significant.

The presence of OM was found to be higher in patients with higher body weight and those on a busulphan-based regimen. Patients with a higher BMI and BSA had a significantly higher incidence of mucositis in this study. This may be due to larger absolute doses of chemotherapy used. Busulphan, which was administered according to the actual body weight, may have influenced this outcome. A higher number of OM in busulphanbased regimens have been similarly demonstrated (Styler et al., 2015). The best model for dosing busulphan whether based on ideal body weight, actual body weight, or adjusted body weight in normal or obese patients is still controversial. Some recommendations lean toward using models that yield the lowest dose (Bacigalupo et al., 2009; Styler et al., 2015) or using adjusted ideal body weight in obese patients (Gibbs et al., 1999). Whether these would have resulted in over-dosing when the actual body weight was used, resulting in a higher incidence of $\mathrm{OM}$ in this study warrants further investigation. The presence of OM was also associated with a longer duration of hospitalization in the current work. Mucositis-driven limitations in diet, increased requirements for mouth care, and pain management contribute to delays in discharge (Wardley et al., 2000).

Most of the reported pain episodes achieved some degree of pain relief with the analgesics administered. However, patients on systemic opioids reported little to no pain relief. It has been reported that Asian patients tend to have undertreated pain, especially in more chronic settings (Chen et al., 2012; de Wit et al., 1999). Poor pain control could be due to the reluctance to request for stronger analgesics, fear of adverse effects, and opioid addiction or tolerance (Manji et al., 2012; Salvador et al., 2012). These findings correspond with previous research and serve to substantiate both the presence of pain and the challenge of managing it successfully. The differences in perception between patients and clinicians on the pain severity of OM have been a major limitation in optimum management. In patients, the mildest symptoms can trigger discomfort, while clinicians look for more complex manifestations such as infections. The time at which patients are assessed may also contribute to variations in reporting.

The use of a tool that is able to accurately measure both the patient and clinician's concern is required (Fadilah et al., 2008). As evident, an overall positive correlation was observed between OMDQ and WHO scales. This was further supported by positive correlations for each component of the scale. This is not unexpected since the WHO scale incorporates both objective assessments of the oral cavity and subjective assessments of the condition of the patient. Among the varying components of OMDQ that assessed patients' functional status, the sleeping component was least correlated. Whether this finding could be related to opiates disruption of sleep (Boonstra et al., 2010; Breuer et al., 2011; Moore and Kelz, 2009) or other factors such as drug side effects (e.g. anti-nausea medications causing insomnia), chemotherapy side effects (e.g. diarrhea, nausea, or vomiting causing sleep disruptions), or emotional status and mood (Boonstra et al., 2010; Breuer et al., 2011) requires further investigation. The fair correlation between diarrhea and overall diarrhea between the two scales may be due to the WHO scale that focuses solely on assessments related to the oral cavity and does not account for mucositis of the other areas of the gastrointestinal tract. The overall health component in OMDQ, however, was also only fairly correlated with the WHO scale and may be related to the multitude of other issues faced by patients such as lethargy, gastrointestinal pain, muscle aches, nausea, and vomiting (Kartin et al., 2014), which is not addressed by the other questions in the OMDQ or WHO scale.

There were a few limitations to the current work. First, while this study highlighted several interesting findings, the small sample size would limit the generalizability of the outcome beyond the immediate sample, although it may be helpful when faced with similar patient populations. Furthermore, as with all self-reported studies, results of the work are dependent on the honesty of the respondents when filling in the OMDQ diaries. Finally, the differences in treatment of OM could also lead to different pain responses in the OMDQ scales when compared to the WHO scales. Therefore, performing the study among a larger set of HSCT patients could allow for sub-analysis of OM grades and treatment type, to ensure a more accurate understanding of OM pain between grades.

\section{CONCLUSION}

In conclusion, this data provide important preliminary insight into the scope and impact of OM in the Malaysian HSCT setting. It is clear from the data that OM pain continues to be a clinical problem in this type of patient population and emphasis should be placed to determine the problem and to ultimately decrease OM distress. The use of the OMDQ self-reported scales could lead to earlier changes in therapy and may prove useful in transplant patients when used in conjunction with the clinicianassessed WHO scale.

\section{ACKNOWLEDGMENTS}

The authors wish to acknowledge Dr. C. Kian Meng, Dr. M. Z. Zakaria, Dr. G. Ai Sim, and Dr. C. Su Kien for their assistance.

\section{REFERENCES}

Abdul Wahid SF, Ismail NA, Mohd-Idris MR, Jamaluddin FW, Tumian N, Sze-Wei EY, Muhammad N, Nai ML. Comparison of reduced-intensity and myeloablative conditioning regimens for allogeneic hematopoietic stem cell transplantation in patients with acute myeloid 
leukemia and acute lymphoblastic leukemia: a meta-analysis. Stem Cells Dev, 2014; 23(21):2535-52.

Bacigalupo A, Ballen K, Rizzo D, Giralt S, Lazarus H, Ho V, Apperley J, Slavin S, Pasquini M, Sandmaier BM, Barrett J, Blaise D, Lowski R, Horowitz M. Defining the intensity of conditioning regimens: working definitions. Biol Blood Marrow Transplant, 2009; 15(12):1628-33.

Bensinger W, Schubert M, Ang KK, Brizel D, Brown E, Eilers JG, Elting L, Mittal BB, Schattner MA, Spielberger R, Treister NS, Trotti AM. Task force report: prevention and management of mucositis in cancer care. J Natl Compr Cancer Netw, 2008; 6(11):1-21.

Boonstra L, Harden K, Jarvis S, Palmer S, Kavanaugh-Carveth P, Barnett J, Friese C. Sleep disturbance in hospitalized recipients of stem cell transplantation. Clin J Oncol Nurs, 2010; 15(3):271-6.

Breuer B, Fleishman SB, Cruciani RA, Portenoy RK. Medical oncologists' attitudes and practice in cancer pain management: a national survey. J Clin Oncol, 2011; 29:4769-75.

Chai WL, Ngeow WC, Abdul Rahman R, Ramli R. Managing complications of radiation therapy in head and neck cancer patients: part $\mathrm{V}$. Management of mucositis. Singapore Dent J, 2006; 28:16-8.

Chen $\mathrm{CH}$, Tang ST, Chen $\mathrm{CH}$. Meta-analysis of cultural differences in Western and Asian patient-perceived barriers to managing cancer pain. Palliat Med, 2012; 26(3):206-21.

de Wit R, van Dam F, Abu-Saad HH, Loonstra S, Zandbelt L, van Buuren A, van der Heijden K, Leenhouts G. Empirical comparison of commonly used measures to evaluate pain treatment in cancer patients with chronic pain. J Clin Oncol, 1999; 17:1280-7.

Fadilah SA, Leong CF, Cheong SK. Stem cell transplantation in Malaysia and future directions. Med J Malaysia, 2008; 63(4):279.

Gibbs JP, Gooley T, Corneau B, Murray G, Stewars P, Appelbaum FR, Slattery JT. The impact of obesity and disease on busulfan oral clearance in adults. Blood, 1999; 93(12):4436-40.

Kartin PT, Tasci S, Soyuer S, Elmali F. Effect of an oral mucositis protocol on quality of life of patients with head and neck cancer treated with radiation therapy. Clin J Oncol Nurs, 2014; 18(6):E118-25.

Loh M, Chua D, Yao Y, Soo RA, Garrett K, Zeps N, Platell C, Minamoto T, Kawakami K, Lacopetta B, Soong R. Can population differences in chemotherapy outcomes be inferred from differences in pharmacogenetic frequencies? Pharmacogenomics J, 2013; 13(5):423-9.

Manji A, Tomlinson D, Ethier M-C, Gassas A, Maloney A-M, Sung L. Psychometric properties of the oral mucositis daily questionnaire for child self-report and importance of mucositis in children treated with chemotherapy. Support Care Cancer, 2012; 20:1251-8.

Moore JT, Kelz MB. Opiates, sleep, and pain: the adenosinergic link. Anesthesiology, 2009; 111(6):1175-6.

Rafeah NT, Fadilah SA. The ABC of haematopoietic stem cell transplantation. Med J Malaysia, 2009; 64(1):94-100.

Salvador P, Azusano C, Wang L, Howell D. A pilot randomized controlled trial of an oral care intervention to reduce mucositis severity in stem cell transplant patients. J Pain Symptom Manag, 2012; 44:64-73.
Sonis ST, Oster G, Fuchs H, Bellm L, Bradford WZ, Edelsberg J, Hayden V, Eilers J, Epstein JB, LeVeque FG, Miller C, Peterson DE, Schubert MM, Spijkervet FKL, Horowitz M. Oral mucositis and the clinical and economic outcomes of hematopoietic stem-cell transplantation. J Clin Oncol, 2001; 19:2201-5.

Stiff PJ, Erder H, Bensinger WI, Emmanouilides C, Gentile T, Isitt J, Lu ZJ, Spielberger R. Reliability and validity of a patient selfadministered daily questionnaire to assess impact of oral mucositis (OM) on pain and daily functioning in patients undergoing autologous hematopoietic stem cell transplantation (HSCT). Bone Marrow Transplant, 2006; 37:393-401.

Styler M, Crilley PA, Jain M, Ward K, Topolsky D, Cho D, Kim M. High-dose melphalan versus busulfan, cyclophosphamide as conditioning regimens for hematopoietic stem cell transplantation in patients with multiple myeloma. Blood, 2015; 126:2001.

Vagliano L, Feraut C, Gobetto G, Trunfio A, Errico A, Campani V, Costazza G, Mega A, Matozzo V, Berni M, Alberani F, Banfi MM, Martinelli1 L, Munaron S, Orlando L, Lubiato L, Leanza S, Guerrato R, Rossetti A, Messina M, Barzetti L, Satta G, Dimonte V. Incidence and severity of oral mucositis in patients undergoing haematopoietic SCTresults of a multicentre study. Bone Marrow Transplant, 2011; 46:727-32.

Wahid SF. Indications and outcomes of reduced-toxicity hematopoietic stem cell transplantation in adult patients with hematological malignancies. Int J Hematol, 2013; 97(5):581-98.

Wardley AM, Jayson GC, Swindell R, Morgenstern GR, Chang J, Bloor R, Fraser CJ, Scarffe JH. Prospective evaluation of oral mucositis in patients receiving myeloablative conditioning regimens and haemopoietic progenitor rescue. Br J Haematol, 2000; 110:292-9.

World Health Organization (WHO). WHO handbook for reporting results of cancer treatment. World Health Organization, Geneva, Switzerland, 1979.

Zhu G, Lin JC, Kim SB, Bernier J, Agarwal JP, Vermorken JB, Thinh DH, Cheng HC, Yun HJ, Chitapanarux I, Lertsanguansinchai P Asian expert recommendation on management of skin and mucosal effects of radiation, with or without the addition of cetuximab or chemotherapy, in treatment of head and neck squamous cell carcinoma. BMC Cancer, 2016; 16(1):42.

How to cite this article:

Wong SP, Islahudin F. A pilot study on effectiveness of oral mucositis pain control in hematopoietic stem cell transplant patients. J Appl Pharm Sci, 2019; 9(03):027-032. 